\title{
Commentary Models of breast cancer: is merging human and animal models the future?
}

\author{
Jong B Kim ${ }^{1}$, Michael J O'Hare ${ }^{1}$ and Robert Stein ${ }^{2}$
}

${ }^{1}$ Department of Surgery, Ludwig Institute for Cancer Research/University College London Breast Cancer Laboratory, Royal Free and University College London Medical School, London, UK

${ }^{2}$ Ludwig Institute for Cancer Research, London, UK

Correspondence: Jong B Kim (e-mail: jong.kim@ucl.ac.uk)

Published: 19 August 2003

Breast Cancer Res 2004, 6:22-30 (DOI 10.1186/bcr645)

(C) 2004 BioMed Central Ltd (Print ISSN 1465-5411; Online ISSN 1465-542X)

See related Commentary, http://breast-cancer-research.com/content/6/1/31

\begin{abstract}
Survival rates of patients with early breast cancer in the United Kingdom and in the United States have improved steadily over the past 15 years. The only way to continue or even accelerate this progress, however, is the discovery and development of new preventative and therapeutic strategies. With the massive explosion in potential therapeutic strategies becoming available, in the postgenomic era, better and more representative breast cancer models are urgently required for preclinical trials. Development of better in vivo models of human breast cancer are thus of crucial importance in the development of new cancer therapeutics.
\end{abstract}

Keywords: breast cancer, immunodeficient mice, in vivo, stroma, xenograft

\section{Introduction}

Breast cancer is the most commonly diagnosed form of cancer and the second leading cause of cancer death in Western women. Between one out of eight and one out of 10 women will develop breast cancer during her lifetime, with the disease being a leading cause of mortality in women over the age of 35 years. Survival rates of patients with early breast cancer in the United Kingdom and in the United States have improved steadily over the past 15 years [1], largely as the result of advances in and improved access to early diagnosis and more effective therapy. Additional gains, however, will require new preventative and therapeutic strategies that require better understanding of the genetics and biology of human breast cancer. Such knowledge, which is rapidly accruing as the result of postgenomic technologies such as proteomics and transcriptional profiling, must be translated into a setting in which potential clinical responsiveness can be evaluated. This in turn requires better in vitro and in vivo models of human breast cancer.

Although in vitro culture of established breast cancer cell lines is probably the most widely used model for such pre- clinical evaluation, it is limited in so far as it contains no stromal cells and, as generally used, lacks three-dimensional structure. These limitations make it poorly representative of real cancers. Animal models in which stroma and structure are present should, if they are to be useful, possess genetic and other biomarker abnormalities similar to, if not identical to, their human counterparts. The most direct way to achieve this is to merge human and animal models in the form of heterotransplanted tissues, implanted either heterotopically (subcutaneous) or orthotopically (mammary fad pad). This commentary discusses the basic concepts of current 'xenograft' models and outlines some of their limitations and potential, as compared with syngeneic and genetically engineered (transgenic) rodent models.

\section{Syngeneic and genetically engineered mouse models}

With the recent introduction of syngeneic mouse tumour models, the choices of animal models have improved [2]. However, the most widely used animal models have a limited role in cancer research because the biology of rodents and their tumours differs significantly from that of 
humans and human cancer. The differences in developmental programmes of mouse and humans manifest in many ways, with size being an obvious example. Cellular targets for oncogenic transformation consequently differ in number, in their degree of maturation and in their differentiation in mouse tissues compared with their human counterparts. In the mammary gland, for example, full glandular maturation is contingent on pregnancy in rodents, but not in humans. This has significant implications with regard to the presence, or absence, of multipotential stem cells, and their role in mammary carcinogenesis.

The shorter lifespan of rodents means that observable tumours must have a rapid programme of progression as mice can develop very malignant tumours showing multiple genetic alterations within a relatively short time period (6-18 months). Although the basic mutation frequency is similar in both species, cells of rodent origin are much easier to transform in vitro by oncogene transfection or chemical carcinogens. Possible explanations for the easier transformation include less efficient DNA repair, poorer control of genetic stability, and or altered control of gene expression through processes such as DNA methylation [3]. Another difference lies in immortalization, which is a key step in tumour progression [4], and the ease with which rodent cells become immortalized [5,6]. Mouse and primary human cells have major differences in telomere dynamics and telomerase regulation. Telomeres are significantly longer in laboratory mice (40-60 kb) compared with in humans $(10 \mathrm{~kb})$, and the enzyme telomerase is widely expressed in adult mouse tissues. In contrast, human cancer cells have acquired the capacity to maintain telomeres through the reactivation of telomerase or other mechanisms to avoid replicative senescence.

Although rodents are intrinsically more susceptible to carcinogenesis, sporadic cancers are quite rare in wild-type rodents. Many decades have been devoted to selective inbreeding to enhance the incidence of specific tumours to useful levels in syngeneic mice, thus altering the genetic background in each strain. Mouse strains susceptible to mammary cancer were isolated many years ago, with vertical transmission (Bittner or milk factor) subsequently shown to be due to a mouse mammary tumour virus. Viruses have yet to be convincingly implicated in human breast cancer, except as possible cofactors [7]. Chemical carcinogenesis has been used in rats to enhance mammary tumour formation, again with no direct human parallel, and with enhanced chemically induced mutations, some of which can result in a partial immune response in the incompletely inbred rat strains.

Overall, a smaller number of genetic changes, in comparison to humans, are required for rodent cell transformation in vitro [8], and this is probably also true for rodent tumours in vivo. This may contribute to the notable differ- ences in tumour biology and pathology observed between the species. For example, about one-half of human breast cancers are hormone responsive at diagnosis, while the vast majority of mouse tumours are hormone independent with much lower levels of oestrogen/progesterone receptors than human tumours [9]. Although similar morphological patterns can be seen in lesions in both species, the detailed morphology of most mouse tumours do not resemble the common human breast cancers and cannot be classified in an equivalent manner to the standard human tumour pathology grades and types $[10,11]$. Rat tumours are likewise distinct, and differ from both mouse and human counterparts in detailed histology. The metastatic patterns between the species are also different.

Breast cancer in humans usually spreads lymphatically, starting with local lymph glands, followed by distant metastasis predominantly to the bone, the brain, the adrenal gland, the liver and the lung. In contrast, mouse mammary cancers metastasize almost exclusively to the lung via the haematogeneous route [12]. One other major, but infrequently mentioned, difference between rodent and human cells, whether in vitro or in vivo, relates to their respiratory quotient. Small animals, such as mice and rats, consume greater amounts of oxygen on a per-cell basis than larger animals. This will result in very different cellular microenvironments, particularly in relatively avascular and hypoxic tumours, where hypoxia-induced genes may play an important role in growth and differentiation [13]. Larger experimental animals can provide potentially better models of human breast disease in this and other respects, but are seldom used for a variety of nonscientific reasons.

Genetically manipulated animals generated by transgenic and gene-targeting (knockout) technology have undoubtedly contributed tremendously to our understanding of gene function and regulation at the molecular level in the context of the whole organism. However, genetically engineered mice (GEM), like syngeneic rodent models, also present fundamental differences at the level of the organism and the cell. GEM are designed to reproduce very specific aspects of tumour formation and progression, usually but not invariably based on knowledge of human tumour genetics. When using transgenic mice, the extent and type of genetic abnormalities that cause disease must be assessed in relation to those that cause human disease, to decide whether they differ to a degree that makes them an unacceptable model. The precise genetic background on which the abnormal genes are either overexpressed or underexpressed within the tumour cells is also important as it may influence their effects or penetrance.

To date, most oncogene-bearing transgenic mice and tumour suppressor gene knockouts have had a wholebody phenotype, in which all tissues and cells bear the same defect. They thus do not mimic sporadic tumours 
that arise from an initiating mutation affecting a single cell in an otherwise normal microenvironment. These models are effectively the rodent equivalent of human familial cancer syndromes. This problem has to some extent been rectified with the use of cell-type specific promoters to limit gene expression to specific target tissues, and with the use of promoter-specific recombinase-based (cre-lox) mechanisms for eliminating transgenes from specific tissues. However, these methods themselves generate other limitations in respect of mammary tumours, as they frequently depend on hormone-sensitive promoters such as the mouse mammary tumour virus long terminal repeat and whey acidic protein promoter. These promoters have hormone-regulated enhancer elements that are not the natural promoters for the activated oncogenes in human breast cancer. This can lead to inappropriate responses, for example enhanced mammary tumourigenesis caused by pregnancy, whereas pregnancy is protective in humans [11].

Despite these limitations, molecular events that occur in human breast cancer can be reproduced in mice, with the same genes triggering the same molecular events. Interestingly, the mammary tumours that are produced in GEM have phenotypes dissimilar to those in mouse mammary tumour virus-induced or chemically induced mammary tumours, and may have greater similarities with human breast cancers. Examples of human genes triggering similar molecular events in mice include a splice variant of erbB2 in humans, which mimics the transmembrane domain mutations that activate the murine c-erbB2 as the oncogene neu, as well as conditional mutants of the tumour suppressor gene $B R C A 1$ that produce mammary gland tumours in mice $[14,15]$. These syngeneic and GEM models have thus contributed significantly to our understanding of the fundamental aspects of breast cancer genetics, but do not provide sufficient similarity with human tumours for preclinical drug testing [16].

\section{Xenograft models}

The fact that some human breast cancer cell lines form tumours in immunodeficient mice was first reported by Isaacson and Cattanach in 1962 [17]. However, the complexity of the procedures used to render wild-type mice immunodeficient, a combination of surgery (thymectomy) radiation and/or drug treatment, meant that this approach was not widely used until the introduction of the mutant nude mouse. Today the nude (Foxn1) mice and severe combined immunodeficiency (SCID) mice, which have naturally occurring single gene mutations that affect their immune system, are the most commonly used research models in xenograft experiments. Nudes have a chromosome 11 autosomal recessive mutation that causes failure of hair growth and other defects, including thymic epithelial dysgenesis, which renders them T-cell deficient [18].
DNA protein kinase resulting in lack of functional T cells and $B$ cells $[19,20]$. Immunodeficient strains have been developed from other species, including the rat, but are not widely used.

Human breast cancer is one of the more difficult tumours to transplant directly into experimental animals, including nude mice and SCID mice. The reported success (take rates) for invasive human breast cancer is 7-20\% [21], with differences accounted for by site of implantation (orthotopic being better), the age and strain of mice used, and whether hormonal supplementation is used (nude mice have low oestrogen levels, compared with humans). Serially transplantable xenografts are much rarer. Paradoxically, better success has been reported with preinvasive disease samples (ductal carcinoma in situ) [22,23]. It has very recently been reported that subsets of immunophenotypically distinct $\left(\mathrm{CD} 44^{+} / \mathrm{CD} 24^{-}\right)$cells within primary breast tumours have an enhanced take rate as xenografts [24]. Directly established mammary tumour xenograft lines with the capacity to metastasize were not developed until the early 1990s [25], although prior and subsequent to this a number of established in vitro lines have been adapted to xenograft cultures. Some such lines are able to locally invade or metastasize, sometimes as the result of further genetic engineering to a more aggressive phenotype.

There are currently many human xenograft models available for use in breast cancer research (Table 1), most derived from both established cancer cell lines and spontaneously or genetically engineered immortalized normal breast epithelial cells. Among the more commonly used are the MCF10AT and MCF-7 systems, probably because of their ease of use and the wealth of information available on these lines from previous in vitro studies. However, the use of established cancer lines as the source of xenograft models raises a number of questions. Cancer cells that have been adapted to grow in culture are likely to have different environmental requirements to primary breast tumour cells. In vitro establishment is a rare event, found in no more than $1 \%$ of primary cancers [26] and almost certainly involving further selection of an 'establishment' phenotype. Thus, cell selection in conversion to continuous culture line, changes in later generations of cell lines (genetic drift) as well as viral or Mycoplasma infection, mislabelling of individual cell lines, and/or doubts as to their actual tumour of origin are factors that impact on the validity of such models.

By contrast, much less effort has been directed at improving primary tumour engraftment. It has recently been reported that histomorphologically intact primary human breast lesions and cancers can be grown in athymic mice. An experimental model system has been developed in which dissociated cells from surgical breast cancer 
Table 1

\section{Commonly used breast cancer xenograft models}

\begin{tabular}{|c|c|c|}
\hline $\begin{array}{l}\text { Human breast cancer } \\
\text { xenograft model }\end{array}$ & Description & Reference \\
\hline MCF-7 & Breast adenocarcinoma cell line, oestrogen receptor-positive & [37] \\
\hline MCF-7/6 & Oestrogen sensitive & [38] \\
\hline MCF-7 BAG & Immunodeficient xenograft model & [39] \\
\hline MCF-7/hVEGF & hVEGF overexpressing & \\
\hline MCF-7-TAM LT & Long-term tamoxifen-stimulated breast tumour model & [40] \\
\hline MCF-7/neu & Overexpressing oncogene neu & [41] \\
\hline MCF-7-MIII & Oestrogen sensitive & [42] \\
\hline MCF-7Ca & Transfected with human aromatase gene & [43] \\
\hline MT2 & MCF-7 tamoxifen-stimulated tumour with Asp351Tyr mutant oestrogen receptor & [44] \\
\hline MT2 TAM & MCF-7-derived tumour serially passaged with tamoxifen & [40] \\
\hline MT-1 & Oestrogen and progesterone receptor-negative in nude rats & [45] \\
\hline MT-3 & Oestrogen receptor-negative & [45] \\
\hline LY2 & Anti-oestrogen-resistant variant of MCF-7 & [46] \\
\hline UMB-1Ca & Oestrogen-independent variant of MCF-7 & [47] \\
\hline MDA-MB-231 & Oestrogen independent & [48] \\
\hline MDA-MD-231 BAG & Immunodeficient xenograft model & [39] \\
\hline MDA-MB-361 & Brain metastasis-derived breast adenocarcinoma cell line & [49] \\
\hline MDA-MB-435 & Oestrogen receptor-negative & [48] \\
\hline MDA-MB-435A & Ascites model & [50] \\
\hline MDA-MB-435S & Spindle-shaped strain of parent line & [51] \\
\hline MDA-MD-435 BAG & Immunodeficient xenograft model & [39] \\
\hline MDA-MB-453 BAG & Fibroblast growth factor receptor overexpressing & [39] \\
\hline MDA-453/LCC6 & & [52] \\
\hline MDA-MB-468 & Oestrogen receptor-negative metastasis-derived cell line & [49] \\
\hline MDA-MB-453 & Breast adenocarcinoma cell line & [53] \\
\hline MCF10AT & Preneoplastic and proliferative model; nontumourigenic & [54] \\
\hline MCF10AneoN & Transfected with neomycin-resistance gene & [55] \\
\hline MCF10AneoT & T24-Ha-ras-transformed derivative of MCF10A & [55] \\
\hline MCF10DCIS.com & Comedo ductal carcinoma in situ & [56] \\
\hline MC-2 & & [57] \\
\hline MC-5 & & [57] \\
\hline MC-18 & & [57] \\
\hline SK-BR3 & $\begin{array}{l}\text { Breast adenocarcinoma cell line that overexpresses oncogenic protein } \mathrm{p} 185^{\mathrm{HER} 2} \text {; } \\
\text { oestrogen receptor-negative }\end{array}$ & [58] \\
\hline SK-BR3/hVEGF & VEGF overexpressing cell line & [58] \\
\hline BT-20 & Oestrogen receptor-negative & [37] \\
\hline BT-474 & Erb2 overexpressing breast tumour & [59] \\
\hline ZR-75-1 & Oestrogen-dependent breast carcinoma & [60] \\
\hline
\end{tabular}


Table 1 Continued

Commonly used breast cancer xenograft models

\begin{tabular}{|c|c|c|}
\hline $\begin{array}{l}\text { Human breast cancer } \\
\text { xenograft model }\end{array}$ & Description & Reference \\
\hline SUM149 & Inflammmatory breast cancer cell line & [61] \\
\hline SUM159PT & Oestrogen independent & [62] \\
\hline T47D & Oestrogen receptor-positive & [63] \\
\hline T47D-E2 & Tamoxifen naïve tumour & [63] \\
\hline $\mathrm{KPL}-1$ & Oestrogen receptor-positive & [64] \\
\hline $\mathrm{KPL}-4$ & Oestrogen receptor-negative & [65] \\
\hline MaTu & Oestrogen receptor-negative solid human mammary carcinoma cell line & [45] \\
\hline MC4000 & Oestrogen receptor-negative & [45] \\
\hline HТ-39 & Oestrogen receptor-negative & [66] \\
\hline HX99 & & [67] \\
\hline T61 & Oestrogen receptor-positive ductal carcinoma & [68] \\
\hline B37 & & [69] \\
\hline $\mathrm{BO}$ & Oestrogen receptor-positive & [70] \\
\hline Br10 & & [71] \\
\hline SE & & [71] \\
\hline WIBC-9 & Inflammmatory breast cancer cell line & [57] \\
\hline Met-1 & Metastatic breast cancer cell line & \\
\hline MAXF401 & & [72] \\
\hline$M X-1$ & & [73] \\
\hline MAXF 499 & Solid ductal & [74] \\
\hline $\mathrm{NCl} / \mathrm{ADR}$ or MCF-7/ADR & Multidrug-resistant MCF-7 cell line that overexpresses P-glycoprotein & [75] \\
\hline 4296 & Oestrogen receptor-positive & [76] \\
\hline 4049 & Oestrogen receptor-negative & [76] \\
\hline 4151 & & [75] \\
\hline 4134 & & [75] \\
\hline 3366 & & [77] \\
\hline 4000 & & [77] \\
\hline CAL51 & Metastatic model of adenocarcinoma & [78] \\
\hline MA-11 & Oestrogen and progesterone negative receptor in nude rats & [79] \\
\hline H31 & & [80] \\
\hline MARY-X & Inflammatory breast cancer model & [81] \\
\hline HBT 3477 & Adenocarcinoma & [82] \\
\hline $\mathrm{Hs578T}$ & Carcinosarcoma derived, epithelial in origin & [82] \\
\hline C8161 & Breast cancer line with high levels of spontaneous metastasis & [83] \\
\hline M24 $4_{\text {met }}$ & Breast cancer line with high levels of spontaneous metastasis & [83] \\
\hline CaMa 15 & Primary infiltrating ductal breast carcinoma & [37] \\
\hline MaNo 4 & Medullary breast carcinoma & [37] \\
\hline Gl-101 & Metastatic breast tumour line & [25] \\
\hline UISO-BCA-NMT-18 & Primary breast carcinoma & [84] \\
\hline
\end{tabular}


specimens, after mixing with extracellular matrices, have been transplanted into nude mice. These transplanted cells undergo morphogenesis that reflects their original phenotype, and they provide a much more relevant model for studying primary human breast lesions and cancers in vivo [27].

However, even these models that are derived directly from clinical samples have their limitations. Overall, xenografts contain fewer stromal cells and the stroma that does exist is murine in origin, resulting in a chimeric tumour. The biology of chimeric rodent/human tumours can differ significantly from that of humans and can result in unpredictable growth, differentiation or metastatic properties [16]. Another limitation inherent to all xenograft models is the lack of an immune response against the tumour cells. However, there are several potential solutions to the immune response problem in the context of modelling immunotherapies. For example, it has been shown that nondisrupted pieces of tumour biopsy tissues implanted into SCID mice resulted in the coengraftment of tumours plus tumour infiltrating lymphocytes, with tumour infiltrating lymphocytes within the tumour graft remaining functional and responding to lymphocyte cytokines [28]. Human peripheral blood lymphocytes, injected subcutaneously with a human lung tumour into SCID mice, also engraft and display antitumour cytotoxic activity [29]. One could envisage the use of mice that combine the immunodeficiency phenotype of the nude/SCID with engraftment of human bone marrow stem cells.

\section{Future progress}

Better understanding of breast cancer biology has lead to the realization that tumour stromal interactions, including desmoplasia and neo-angiogenesis, are of major importance in cancer biology. Understanding these reciprocal interactions offers the possibility of new potential therapeutic strategies, including those that target breast cancer stroma itself. Tumour fibroblasts, which have an activation phenotype different to that of resting tissue fibroblasts, thus offer a potential target for antitumour therapy [30]. Also, recent reports have shown that cancer stromal alterations precede the malignant conversion of tumour cells [31]. In the light of this new evidence, therapeutic targeting of stromal cells as opposed to (or as well as) epithelial cells is now considered an appropriate strategy [32-34]. Developing better model systems representing both human stromal and epithelial cells will enable these emerging therapies to be tested more critically.

This requirement has long been recognized, but attempts to date have often floundered on the lack of readily available human stroma in a form that can be easily manipulated. Ideally, these xenograft models should represent both stromal and epithelial cells with normal, premalig- nant, preinvasive malignant, invasive malignant and metastatic phenotypes. A novel three-dimensional cell-cell interaction model was recently xenografted into immunodeficient mice. This comprised normal breast fibroblasts derived from reduction mammoplasties, plus normal human umbilical vein endothelial cells in combination with normal and preneoplastic human breast epithelial cells derived from clinical samples [35]. However, the model has some deficiencies. Key among these is the difficulty in assembling such cell combinations on a long-term and reproducible basis. Normal cell types have a limited lifespan in vitro, and will undergo senescence-related changes if extensively passaged. Reproducibility is also an issue if the cells are freshly isolated for each preparation from different donors. Also, umbilical vein endothelial cells differ from their mature vascular counterparts.

The cells used for such mix-and-match combinations should ideally be derived from the breast, be capable of being generated without donor or passage-related differences, and be available in limitless quantities. With the recent development of immortalized human adult mammary stromal cells [36], it has now become possible to satisfy these criteria and to perhaps develop a fully 'humanized' breast cancer model in immunodeficient mice. Both endothelial cells and fibroblasts were immortalized using a combination of retroviral transduction of the catalytic subunit of human telomerase plus mutant variants of the SV40 T-antigen gene. Despite its name, the large T protein does not transform the stromal cells, but it does unlock their indefinite proliferation, provided that telomeric erosion is prevented by the telomerase activity present in the cells. Neither gene singly was capable of full immortalization of these cells.

The availability of cells that are conditionally immortalized (temperature sensitive) as well as nontemperature-sensitive variants from the same individual donor stocks enables different combinations of quiescent and proliferatively active cells to be generated. In this way, the response of tumour cells to continued stromal proliferation (equivalent to desmoplasia and neo-angiogenesis) can be examined, as well as the response of quiescent stromal cells to the presence of proliferating tumour. Preliminary experiments have shown that multicellular spheroids composed of mammary epithelial, endothelial and fibroblastic cell types can be created in vitro using 'zero gravity' culture vessels, as a step towards the engraftment of such aggregates in nude mice. We envisage that such models will initially comprise combinations of xenograftable tumours derived directly from primary clinical material, rather than pre-adapted cell lines, in combination with the immortalized stromal cells; however, such combinations could substitute purified primary tumour cells from invasive or in situ carcinoma types. 


\section{Conclusion}

Good models for preclinical testing must not only reproduce the pathology and behaviour of human tumours, but must also be highly reproducible with predictable endpoints. To enable mouse xenograft models to be used in routine screening of preventative and therapeutic strategies, they must reflect the cellular composition of 'real' tumours but also be simple to construct and preferably not too costly. Barriers to progress include an attitude that animal model and tumour cell line development is not critical research, restricted access to existing animal models and, finally, difficulties that pertain to the direct access and use of fresh clinical materials on a routine basis. Although considerable difficulties will be encountered in the generation and use of such complex models, their potential value in the longer term is such that every effort should be made to develop them.

\section{Competing interests}

None declared.

\section{Acknowledgements}

The authors thank Ludwig Institute for Cancer Research for its support and funding, and Dr Suzanne Eccles (Institute of Cancer Research) for help and advice.

\section{References}

1. Peto R, Boreham J, Clarke M, Davies C, Beral V: UK and USA breast cancer deaths down $25 \%$ in year 2000 at ages $20-69$ years [letter]. Lancet 2000, 355:1822.

2. Shi HY, Zhang W, Liang R, Abraham S, Kittrell FS, Medina D, Zhang M: Blocking tumour growth, invasion, and metastasis by maspin in a syngeneic breast cancer model. Cancer Res 2001, 61:6945-6951.

3. Holliday R: Neoplastic transformation: the contrasting stability of human and mouse cells. Cancer Surv 1996, 28:103-115.

4. Hanahan D, Weinberg RA: The hallmarks of cancer. Cell 2000, 100:57-70.

5. Newbold RF: Genetic control of telomerase and replicative senescence in human and rodent cells. Ciba Found Symp 1997, 211:177-189.

6. Greenberg RA, Allsopp RC, Chin L, Morin GB, DePinho RA: Expression of mouse telomerase reverse transcriptase during development, differentiation and proliferation. Oncogene 1998, 16:1723-1730.

7. Wong M, Pagano JS, Schiller JT, Tevethia SS, Raab-Traub N, Gruber J: New associations of human papillomavirus, Simian virus 40, and Epstein-Barr virus with human cancer. $J$ Natl Cancer Inst 2002, 94:1832-1836.

8. Balmain A, Harris CC: Carcinogenesis in mouse and human cells: parallels and paradoxes. Carcinogenesis 2000, 21:371377.

9. Nandi S, Guzman RC, Yang J: Hormones and mammary carcinogenesis in mice, rats, and humans: a unifying hypothesis. Proc Natl Acad Sci USA 1995, 92:3650-3657.

10. Cardiff RD, Anver MR, Gusterson BA, Hennighausen L, Jensen RA, Merino MJ, Rehm S, Russo J, Tavassoli FA, Wakefield LM, Ward JM, Green JE: The mammary pathology of genetically engineered mice: the consensus report and recommendations from the Annapolis meeting. Oncogene 2000, 19:968988.

11. Cardiff RD: Validity of mouse mammary tumour models for human breast cancer: comparative pathology. Microsc Res Tech 2001, 52:224-230.

12. Cheung ATW, Young LJT, Chen PCY, Chao CY, Ndoye A, Barry PA, Muller WJ, Cardiff RD: Microcirculation and metastasis in a new mouse mammary tumor model system. Int J Oncol 1997,
13. Helczynska K, Kronblad A, Jogi A, Nilsson E, Beckman S, Landberg G, Pahlman S: Hypoxia promotes a dedifferentiated phenotype in ductal breast carcinoma in situ. Cancer Res 2003, 63:1441-1444.

14. Andrechek ER, Hardy WR, Siegel PM, Rudnicki MA, Cardiff RD, Muller WJ: Amplification of the neu/erbB-2 oncogene in a novel mouse model of mammary tumorigenesis. Proc Natl Acad Sci 2000, 97:3444-3449.

15. Deng CX, Scott F: Role of the tumor suppressor gene Brca1 in genetic stability and mammary gland tumor formation. Oncogene 2000, 19:1059-1064.

16. Hahn WC, Weinberg RA: Modelling the molecular circuitry of cancer. Nat Rev Cancer 2002, 2:331-341.

17. Isaacson JH, Cattanach BM: [Report]. Mouse News Lett 1962, 27:31.

18. Kindred B: Antibody response in genetically thymus-less nude mice injected with normal thymus cells. J Immunol 1971, 107:1291-1295.

19. Bosma MJ, Carroll AM: The SCID mouse mutant: definition, characterization, and potential uses. Annuv Rev Immunol 1991, 9:323-350.

20. Nakajima PB, Bosma MJ: Variable diversity joining recombination: nonhairpin coding ends in thymocytes of SCID and wild type mice. J Immunol 2002, 169:3094-3104.

21. Mehta RR, Graves JM, Hart GD, Shilkaitas A, DasGupta TK: Growth and metastasis of human breast carcinomas with matrigel in athymic mice. Breast Cancer Res Treat 1993, 25: 65-71.

22. Gandhi A, Holland PA, Knox WF, Potten CS, Bundred NJ: Effects of a pure antiestrogen on apoptosis and proliferation within human breast ductal carcinoma in situ. Cancer Res 2000, 60: 4284-4288.

23. Chan KC, Knox WF, Gee JM, Morris J, Nicholson RI, Potten CS, Bundred NJ: Effect of epidermal growth factor receptor tyrosine kinase inhibition on epithelial proliferation in normal and premalignant breast. Cancer Res 2002, 62:122-1288.

24. Al-Hajj M, Wicha MS, Benito-Hernandez A, Morrison SJ, Clarke MF: Prospective identification of tumorigenic breast cancer cells. Proc Natl Acad Sci USA 2003, 100:3983-3988.

25. Hurst J, Maniar N, Tombarkiewicz J, Lucas F, Roberson C, Steplewski Z, James W, Perras J: A novel model of a metastatic human breast tumour xenograft line. $\mathrm{Br} J$ Cancer 1993, 68: 274-276.

26. O'Hare MJ: Breast cancer. In Human Cancer in Primary Culture, A Handbook. Edited by Masters JRW. London: Kluwer Academic Publishers; 1991:271-286.

27. Yang J, Guzman R, Nandi S: Histomorphologically intact primary human breast lesions and cancers can be propagated in nude mice. Cancer Lett 2000, 159:205-210.

28. Sugiyama $Y$, Kato M, Chen FA, Williams SS, Kawaguchi $Y$, Miya $K$, Jong YS, Mathiowitz E, Egilmez NK, Bankert RB: Human inflammatory cells within the tumor microenvironment of lung tumor xenografts mediate tumor growth suppression in situ that depends on and is augmented by interleukin-12. $J$ Immunother 2001, 24:37-45.

29. Iwanuma Y, Chen F-A, Egilmez NK, Takita H, Bankert RB: Antitumor immune response of human peripheral blood lymphocytes coengrafted with tumor into severe combined immunodeficient mice. Cancer Res 1997, 57:2937-2942.

30. Mersmann M, Schmidt A, Rippmann JF, Wuest T, Brocks B, Rettig WJ, Garin-Chesa P, Pfizenmaier K, Moosmayer D: Human antibody derivatives against the fibroblast activation protein for tumor stroma targeting of carcinomas. Int J Cancer 2001, 92:240-248.

31. Moinfar F, Man YG, Arnould L, Bratthauer GL, Ratschek M, Tavassoli $F$ : Concurrent and independent genetic alterations in the stromal and epithelial cells of mammary carcinoma: implications for tumorigenesis. Cancer Res 2000, 60:2562-2566.

32. Camps JL, Chang S, Hsu TC, Freeman MR, Hong S, Zhau HE, von Eschenbach AC, Chung LWK: Fibroblast-mediated acceleration of human epithelial tumor growth in vivo. Proc Natl Acad Sci USA 1990, 87:75-79.

33. Picard O, Rolland Y, Poupon MF: Fibroblast-dependent tumorigenicity of cells in nude mice. Cancer Res 1986, 46:3290-3294.

34. Grey AM, Schor AM, Rushton G, Ellis I, Schor SL: Purification of the migration-stimulating factor produced by fetal and breast cancer patient fibroblasts. Proc Natl Acad Sci USA 1989, 86: 2438-2442. 
35. Shekhar MPV, Werdell J, Santner SJ, Pauley RJ, Tait L: Breast stroma plays a dominant regulatory role in breast epithelial growth and differentiation: implications for tumor development and progression. Cancer Res 2001, 61:1320-1326.

36. O'Hare MJ, Bond J, Clarke C, Takeuchi Y, Atherton AJ, Berry C, Moody J, Silver AR, Davies DC, Alsop AE, Neville AM, Jat PS: Conditional immortalization of freshly isolated human mammary fibroblasts and endothelial cells. Proc Natl Acad Sci USA 2001, 98:646-651.

37. Ozzello L, Sordat M: Behavior of tumors produced by transplantation of human mammary cell lines in athymic nude mice. Eur J Cancer 1980, 16:553-559.

38. Trouet A, Passioukov A, Van derpoorten K, Fernandez AM, Abarca-Quinones J, Baurain R, Lobl TJ, Oliyai C, Shochat D, Dubois V: Extracellularly tumor-activated prodrugs for the selective chemotherapy of cancer: application to doxorubicin and preliminary in vitro and in vivo studies. Cancer Res 2001, 61:2843-2846

39. Brünner N, Thompson EW, Spang-Thomsen M, Rygaard J, Danø $\mathrm{K}$, Zwiebel J: A lacZ transduced human breast cancer xenografts as an in vivo model for the study of invasion and metastasis. Eur J Cancer 1992, 28A:1989-1995.

40. Yao K, Lee ES, Bentrem DJ, England G, Schafer Jl, O'Regan RM, Jordan VC: Antitumor action of physiological estradiol on tamoxifen-stimulated breast tumors grown in athymic mice. Clin Cancer Res 2000, 6:2028-2036.

41. Yi B, Williams PJ, Niewolna M, Wang Y, Yoneda T: Tumorderived platelet-derived growth factor-BB plays a critical role in osteosclerotic bone metastasis in an animal model of human breast cancer. Cancer Res 2002, 62:917-923.

42. Kahan Z, Nagy A, Schally AV, Hebert F, Sun B, Groot K, Halmos G: Inhibition of growth of MX-1, MCF-7-MIII and MDA-MB-231 human breast cancer xenografts after administration of a targeted cytotoxic analog of somatostatin, AN-238. Int J Cancer 1999, 82:592-598.

43. Long BJ, Jelovac D, Thiantanawat A, Brodie AM: The effect of second-line antiestrogen therapy on breast tumor growth after first-line treatment with the aromatase inhibitor letrozole: long-term studies using the intratumoral aromatase postmenopausal breast cancer model. Clin Cancer Res 2002, 8:2378-2388.

44. Leuschner C, Enright FM, Gawronska B, Hansel W: Membrane disrupting lytic peptide conjugates destroy hormone dependent and independent breast cancer cells in vitro and in vivo. Breast Cancer Res Treat 2003, 78:17-27.

45. Hambly RJ, Double JA, Thompson MJ, Bibby MC: Establishment and characterisation of new cell lines from human breast tumours initially established as tumour xenografts in NMRI nude mice. Breast Cancer Res Treat 1997, 43:247-258.

46. Gottardis MM, Lamph WW, Shalinsky DR, Wellstein A, Heyman RA: The efficacy of 9-cis retinoic acid in experimental models of cancer. Breast Cancer Res Treat 1996, 38:85-96.

47. Herrera-Gayol A, Jothy S: Effect of hyaluronan on xenotransplanted breast cancer. Exp Mol Pathol 2002, 72:179-185.

48. Price JE, Polyzos A, Zhang RD, Daniels LM: Tumorigenicity and metastasis of human breast carcinoma cell lines in nude mice. Cancer Res 1990, 50:717-721.

49. Zhang RD, Fidler IJ, Price JE: Relative malignant potential of human breast carcinoma cell lines established from pleural effusions and a brain metastasis. Invasion Metastasis 1991, 11:204-215.

50. Van den Berg CL, Cox GN, Stroh CA, Hilsenbeck SG, Weng CN, McDermott MJ, Pratt D, Osborne CK, Coronado-Heinsohn EB, Yee D: Polyethylene glycol conjugated insulin-like growth factor binding protein-1 (IGFBP-1) inhibits growth of breast cancer in athymic mice. Eur J Cancer 1997, 33:1108-1113.

51. Alpaugh ML, Tomlinson JS, Ye Y, Barsky SH: Relationship of sialyl-Lewis $(x / a)$ underexpression and E-cadherin overexpression in the lymphovascular embolus of inflammatory breast carcinoma. Am J Patho/ 2002, 161:619-628.

52. Lopes D, Mayer LD: Pharmacokinetics of $\mathrm{Bcl}-2$ antisense oligonucleotide (G3139) combined with doxorubicin in SCID mice bearing human breast cancer solid tumor xenografts. Cancer Chemother Pharmacol 2002, 49:57-68.

53. Colbern GT, Hiller AJ, Musterer RS, Working PK, Henderson IC: Antitumor activity of Herceptin in combination with STEALTH liposomal cisplatin or nonliposomal cisplatin in a HER2 posi- tive human breast cancer model. J Inorg Biochem 1999, 77: 117-120.

54. Dawson PJ, Wolman SR, Tait L, Heppner GH, Miller FR: MCF10AT: a model for the evolution of cancer from proliferative breast disease. Am J Pathol 1996, 148:313-319.

55. Miller FR, Soule HD, Tait L, Pauley RJ, Wolman SR, Dawson PJ, Heppner GH: Xenograft model of progressive human proliferative breast disease. J Natl Cancer Inst 1993, 85:1725-1732.

56. Miller FR, Santner SJ, Tait L, Dawson PJ: MCF10DCIS.com xenograft model of human comedo ductal carcinoma in situ. J Natl Cancer Inst 2000, 92:1185-1186.

57. Shirakawa K, Tsuda H, Heike $Y$, Kato K, Inomata M, Sasaki H, Kasumi F, Yoshimoto M, Iwanaga T, Konishi F, Terada M, Wakasugi $H$ : Absence of endothelial cells, central necrosis, and fibrosis are associated with aggressive inflammatory breast cancer. Cancer Res 2001, 61:445-451.

58. Shirakawa K, Furuhata S, Watanabe I, Hayase $H$, Shimizu A, Ikarashi Y, Yoshida T, Terada M, Hashimoto D, Wakasugi H: Induction of vasculogenesis in breast cancer models. $\mathrm{Br}$ Cancer 2002, 87:1454-1461.

59. Kubota T, Oka S, Utsumi T, Inoue S, Kuzuoka M, Suto A, Arisawa $Y$, Ishibiki K, Abe O: Human breast carcinoma (ZR-75-1) serially transplanted into nude mice - with reference to estradiol dependency and sensitivity to tamoxifen. Jpn J Surg 1989, 19: 446-451.

60. Monsky WL, Mouta Carreira C, Tsuzuki Y, Gohongi T, Fukumura $D$, Jain RK: Role of host microenvironment in angiogenesis and microvascular functions in human breast cancer xenografts: mammary fat pad versus cranial tumors. Clin Cancer Res 2002, 8:1008-1013.

61. Pan Q, Kleer CG, van Golen KL, Irani J, Bottema KM, Bias C, De Carvalho M, Mesri EA, Robins DM, Dick RD, Brewer GJ, Merajver SD: Copper deficiency induced by tetrathiomolybdate suppresses tumor growth and angiogenesis. Cancer Res 2002, 62:4854-4859.

62. Flanagan L, Van Weelden $\mathrm{K}$, Ammerman C, Ethier SP, Welsh J: SUM-159PT cells: a novel estrogen independent human breast cancer model system. Breast Cancer Res Treat 1999, 58:193-204.

63. Schafer JM, Lee ES, Dardes RC, Bentrem D, O'Regan RM, De Los Reyes A, Jordan VC: Analysis of cross-resistance of the selective estrogen receptor modulators arzoxifene (LY353381) and LY117018 in tamoxifen-stimulated breast cancer xenografts. Clin Cancer Res 2001, 7:2505-2512.

64. Kurebayashi J, Kurosumi M, Sonoo H: A new human breast cancer cell line, KPL-1 secretes tumour-associated antigens and grows rapidly in female athymic nude mice. $\mathrm{Br} J$ Cancer 1995, 71:845-853.

65. Kurebayashi J, Yamamoto S, Otsuki T, Sonoo H: Medroxyprogesterone acetate inhibits interleukin 6 secretion from KPL-4 human breast cancer cells both in vitro and in vivo: a possible mechanism of the anticachectic effect. Br J Cancer 1999, 79: 631-636.

66. Rampy MA, Brown RS, Pinchuk AN, Weichert JP, Skinner RW, Fisher SJ, Wahl RL, Gross MD, Ethier SP, Counsell RE: Biological disposition and imaging of a radioiodinated alkylphosphocholine in two rodent models of breast cancer. $J$ Nucl Med 1996, 37:1540-1545.

67. Dardes RC, O'Regan RM, Gajdos C, Robinson SP, Bentrem D, De Los Reyes A, Jordan VC: Effects of a new clinically relevant antiestrogen (GW5638) related to tamoxifen on breast and endometrial cancer growth in vivo. Clin Cancer Res 2002, 8: 1995-2001.

68. Brunner N, Bastert GB, Poulsen HS, Spang-Thomsen M, Engelholm SA, Vindelov L, Nielsen A, Tommerup N, Elling F: Characterization of the T61 human breast carcinoma established in nude mice. Eur J Cancer Clin Oncol 1985, 21:833-843.

69. Li HY, Li Y, Liu ZH, Wu HJ, Chen FH, Chen XG: Studies on antitumor activity of rhEndostatin. Yao Xue Xue Bao 2002, 37:763-766.

70. Shi DF, Bradshaw TD, Wrigley S, McCall CJ, Lelieveld P, Fichtner I, Stevens MF: Antitumor benzothiazoles. 3. Synthesis of 2-(4aminophenyl)benzothiazoles and evaluation of their activities against breast cancer cell lines in vitro and in vivo. $J \mathrm{Med}$ Chem 1996, 39:3375-3384.

71. Kelland LR, Steel GG: Dose-rate effects in the radiation response of four human tumour xenografts. Radiother Oncol $1986,7: 259-268$ 
72. Fujimoto-Ouchi K, Tanaka Y, Tominaga T: Schedule dependency of antitumor activity in combination therapy with capecitabine/5'-deoxy-5-fluorouridine and docetaxel in breast cancer models. Clin Cancer Res 2001, 7:1079-1086.

73. Borch RF, Liu J, Joswig C, Baggs RB, Dexter DL, Mangold GL: Antitumor activity and toxicity of novel nitroheterocyclic phosphoramidates. J Med Chem 2001, 44:74-77.

74. Burger AM, Hartung G, Stehle G, Sinn H, Fiebig HH: Pre-clinical evaluation of a methotrexate-albumin conjugate (MTX-HSA) in human tumor xenografts in vivo. Int J Cancer 2001, 92:718724.

75. Dehmel A, Becker M, Lemm M, Fichtner I: Expression of CD44 isoforms in human breast carcinoma xenografts is not influenced by the treatment of mice with cytostatics or (anti-hormones). Anticancer Res 1999, 19:1977-1987.

76. Naundorf H, Fichtner I, Elbe B, Saul GJ, Haensch W, Zschiesche W, Reinecke S: Establishment and characteristics of two new human mammary carcinoma lines in nude mice with special reference to the estradiol receptor status and the importance of stroma for in vivo and in vitro growth. Breast Cancer Res Treat 1994, 32:187-196.

77. Naundorf H, Zschiesche W, Reszka R, Fichtner I: Influence of liposomes rich in unsaturated or saturated fatty acids on the growth of human xenotransplanted mammary carcinomas and on the levels of heart type fatty acid binding protein. In Vivo 1995, 9:247-251.

78. Victor R, Chauzy C, Girard N, Gioanni J, d'Anjou J, Stora De Novion H, Delpech B: Human breast-cancer metastasis formation in a nude-mouse model: studies of hyaluronidase, hyaluronan and hyaluronan-binding sites in metastatic cells. Int J Cancer 1999, 82:77-83.

79. Rye PD, Norum L, Olsen DR, Garman-Vik S, Kaul S, Fodstad Ø: Brain metastasis model in athymic nude mice using a novel MUC1-secreting human breast-cancer cell line MA11. Int J Cancer 1996, 68:682-687.

80. Ikegami Y, Yano S, Nakao K, Fujita F, Fujita M, Sakamoto Y, Murata N, Isowa K: Antitumor activity of the new selective protein kinase $C$ inhibitor $4^{\prime}-N$-benzoyl staurosporine on murine and human tumor models. Arzneimittelforschung 1995, 45:1225-1230.

81. Alpaugh ML, Tomlinson JS, Shao ZM, Barsky SH: A novel human xenograft model of inflammatory breast cancer. Cancer Res 1999, 59:5079-5084.

82. Yue W, Zhou DJ, Chen S, Brodie AMH: A new nude mouse model for postmenopausal breast cancer using MCF-7 cells transfected with the human aromatase gene. Cancer Res 1994, 54:5092-5095.

83. Burke PA, DeNardo SJ, Miers LA, Lamborn KR, Matzku S, DeNardo GL: Cilengitide targeting of alpha(v)beta(3) integrin receptor synergizes with radioimmunotherapy to increase efficacy and apoptosis in breast cancer xenografts. Cancer Res 2002, 62:4263-4272.

84. Mehta RR, Graves JM, Shilkaitis A, Das Gupta TK: Development of a new metastatic human breast carcinoma xenograft line. Br J Cancer 1998, 77:595-604.

\section{Correspondence}

Jong B Kim, Ludwig Institute for Cancer Research/University College London Breast Cancer Laboratory, Department of Surgery, Royal Free and University College London Medical School, Charles Bell House, 67-73 Riding House Street, London W1W 7EJ, UK. Tel: +44 207 679 9044; fax: +44 207679 9508; e-mail: jong.kim@ucl.ac.uk 